\title{
PENINGKATAN KEKERASAN DAN KETAHANAN AUS BAJA KARBON RENDAH DAN BESI COR KELABU MELALUI PROSES VANADISASI
}

\author{
Lukito Dwi Yuono \\ Jurusan Teknik Mesin Universitas Muhammadiyah Metro \\ Jl. Ki Hajar Dewantara no 632 Kota Metro Lampung 34111 0725-41031 \\ Email : Lukitody1@gmail.com
}

\begin{abstract}
The surface hardening process is one of the high temperature treatment processes wich is applied only on the surface of the object of the treatment so that it result an object with superficial hardness without changing the interior matrix shape of the object. The materials used in this research are Perlitics Gray Cast Iron and Low Carbon Steel which are easily avaliable in the market) to increase the hardness and resistance of the surface of the object through vanadisation. As the diffusion material, vanadium, which was derived from ferro vanadium powder was used. The experiment was conducted by varying temperatures of $800^{\circ} \mathrm{C}$ and $875^{\circ} \mathrm{C}$, with the resisting periods of 1 hour, 3 hours, and 5 hours. From this experiment, it was expected that there was anincrease in hardness and resistance of the object surface without changing its interior matrix shape. After conducting the experiment and some test namely metallography test, hardness test, and resistance test, it showed that there was diffusion process on the surface of the object. Having been compared with the sample before the treatment, it can be seen that:

- Based on the result of metallography test, there is a change in the exterior shape of the sample, but a constant interior matrix shape of it.

- Based on the hardness test, there is an increase on hardness, maximally on the sample caded BCK-5/875 to the rate of $742 \mathrm{HV}$.

- Bases on the resistance test, there is an increase also in its rate. It can be seen from the lowest weight loss rate on the sample coded BCK-5/875 to 0,0018 $\mathrm{gr}$.
\end{abstract}

Keywords : Vanadisasi, diffusion process, surface hardening

\section{PENDAHULUAN}

Suatu jenis logam dan paduan logam secara harfiah biasanya mempunyai karakteristik tertentu yang berbeda dengan logam ataupun paduan logam lainnya. Karakteristik tersebut ada yang baik dan ada pula yang kurang baik, tetapi tidak ada satu logam pun yang mempunyai seluruh sifat baik tanpa ada kelemahannya.

Oleh karena itu untuk merubah karakteristik logam sehingga dapat memenuhi tuntutan-tuntutan dalam pemakaiannya dilakukan berbagai perlakuan, salah satu perlakuan yang dimaksud adalah dengan perlakuan panas.

Proses pengerasan permukaan (surface hardening) adalah salah satu proses perlakuan panas dimana proses pengerasan yang dilakukan hanya pada permukaan benda kerja saja sehingga diperoleh bahan yang memiliki kekerasan yang lebih tinggi dan kekerasan bahan awalnya tanpa terjadi perubahan fasa pada struktur matriks bagian dalam bahan.
Terdapat dua cara dalam proses pengerasan permukaan, yaitu:

1. Thermal treatment, yaitu proses yang dilakukan tanpa merubah komposisi kimia atau dapat juga disebut perlakuan panas termal, misalnya flame hardening, induction hardening.

2. Thermochemical treatment, yaitu proses yang dilakukan dengan merubah komposisi kimia atau dapat disebut juga dengan proses perlakuan panas termokimia, misalnya karburasi, nitridasi, karbonitridasi, vanadisasi.

Adapun logam yang akan dicoba diperbaiki

sifatnya dalam penelitian ini adalah besi cor kelabu perlitik (perlitic gray cast iron) dan baja karbon rendah dengan pertimbangan:

Besi cor kelabu perlitik

- $\quad$ Mampu mesin (Machinabilily)

- Mampu menahan getaran (walaupun lebih rendah dan noduler cast iron)

- Dapat menahan tekanan, sebanding dengan kekuatan baja 
- $\quad$ Mampu mesin

Baja karbon rendah

- Mampu bentuk (formability)

- Mampu mesin (Machinability)

- Mampu las (Weldabiliry)

Kelemahan dan kedua bahan tersebut diatas yang dicoba untuk diperbaiki

sifatnya adalah

- Nilai kekerasan yang relatif rendah sehingga dicoba untuk meningkatkan kekerasan pada permukaannya dengan proses vanadisasi dan diperoleh bahan yang mempunyai sifat-sifat yang tidak berubah path bagian dalam dan bahan tapi bersifat keras dipermukaan.

- Ketahanan ausnya relatif rendah sehingga dicoba untuk meningkatkan ketahanan ausnya dengan proses vanadisasi

\section{METODE PENELITIAN}

\section{Bahan}

Bahan-bahan yang digunakan dalam penelitian, adalah :

a) Besi cor kelabu perlitik, dengan komposisi kimia terdiri dari : $416 \% \mathrm{C}, 2,29 \% \mathrm{~S}, 0,001 \%$ P, 0,56 \% Mn, 0,019\% Ni,0,03\% Cr, 0,02\% $\mathrm{Cu}, 92,82 \% \mathrm{Fe}$.

b) Baju karbon rendah, dengan komposisi kimia terdiri dari : $0,21 \% \mathrm{C}, 0,27 \% \mathrm{Si}, 0,02 \% \mathrm{P}, 1,14$ $\% \mathrm{Mn}, 0,01 \% \mathrm{Ni}, 0,03 \% \mathrm{Cr}, 0,03 \% \mathrm{Al}, 98,62$ $\% \mathrm{Fe}$.

c) Bahan vanadium yang digunakan adalah campuran dari serbuk Fe-B (high carbon); NH4CI dan serbuk AI2O3 dengan perbandingan persen berat $: 60: 3,5: 36,5$

\section{Sampel}

Bahan besi cor kelabu perlitik disiapkan dalam bentuk sampel berdasarkan kebutuhan untuk pengujian.

Adapun bentuk ukuran dan ukuran sampel tersebut adalah balok dengan ukuran 10 x 10 x $20 \mathrm{~mm}$.

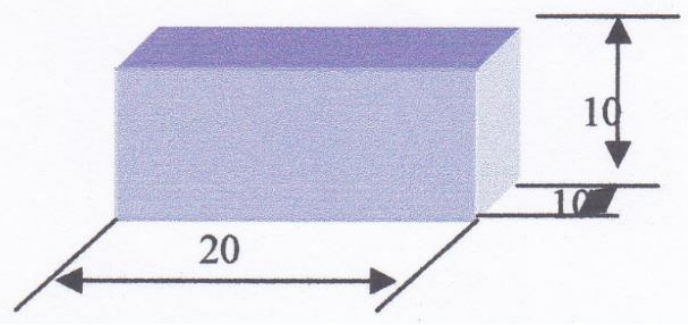

Gambar 1. Ukuran Sampel

\section{Prosedur Percobaan}

Prosedur percobaan proses laku panas vanadium dilakukan melalui tahapan, sebagai berikut :

a. Persiapan bahan awal

Karakteristik besi cor kelabu perlitik, meliputi : analisa komposisis kimia, strukturmikro dan kekerasan . Benda kerja sebelumnya dibentuk melalui mesin frais menjadi bentuk balok yang mempunyai ukuran $10 \times 10 \times 20 \mathrm{~mm}$, dan permukaannya diratakan dengan mesisn perata (surface grinding machine).

b. Masukkan kedalam tabung dari bahan baja tahan karat bersama-sama dengan campuran serbuk yang terdiri dari $\mathrm{Fe}-\mathrm{V}, \mathrm{NH}_{4} \mathrm{CI}$ dan $\mathrm{AI}_{2} \mathrm{O}_{3}$ dengan perbandingan yang atelah ditentukan .Kemudian tutup rapat bagian atas tabung dengan penutup dari bahan yang sama, agar gas yang terbentuk pada saat pemanasan berlangsung tidjak keluar atau bocor.

c. Proses laku panas Vanadisasi dilakukan pada temperature pemanasan $800^{\circ}$, dan $875^{\circ}$ dengan waktu penahanan selama 1,3 , dan 5 jam. Sedangkan pendinginan dilakukan di udara terbuka. Tabel di bawah ini menunjukkan kode sampel yang dipakai dalam penelitian.

d. Setelah proses Vanadisasi selesai, kemudian dilakukan pengujian yang meliputi pengukuran kedalaman lapisan yang terbentuk dipermukaan benda kerja, uji kekerasan dan uji ketahanan aus.

Posisi benda kerja di dalam tabung baja tahan karat dan kurva proses perlakuan panasnya, ditunjukkan pada Gambar 2 dan 3.

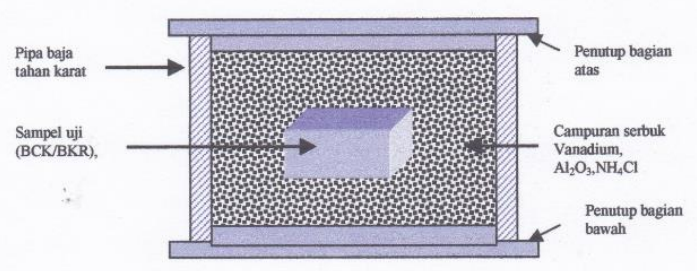

Gambar 2. Pemasangan Benda Uji 
Tabel 1 .Pemberian kode sampel

\begin{tabular}{cccc}
\hline & & \multicolumn{2}{c}{ Kondisi Proses Vanadisasi } \\
\hline No & $\begin{array}{c}\text { Kode } \\
\text { Sampel }\end{array}$ & $\begin{array}{c}\text { Temperatur } \\
\text { Vanadisasi } \\
\left({ }^{\mathbf{0} C)}\right.\end{array}$ & $\begin{array}{c}\text { Waktu } \\
\text { Penahan } \\
\text { (jam) }\end{array}$ \\
\hline 1 & BCK 800-1 & 800 & 1 \\
2 & BCK 800-3 & 800 & 3 \\
3 & BCK 800-5 & 800 & 5 \\
4 & BCK 800-1 & 875 & 1 \\
5 & BCK 875-3 & 875 & 3 \\
6 & BCK 875-5 & 875 & 5 \\
7 & BKR 800-1 & 800 & 1 \\
8 & BKR 800-3 & 800 & 3 \\
9 & BKR 800-5 & 800 & 5 \\
10 & BKR 875-1 & 875 & 1 \\
11 & BKR 875-3 & 875 & 3 \\
12 & BKR 875-5 & 875 & 5 \\
\hline
\end{tabular}

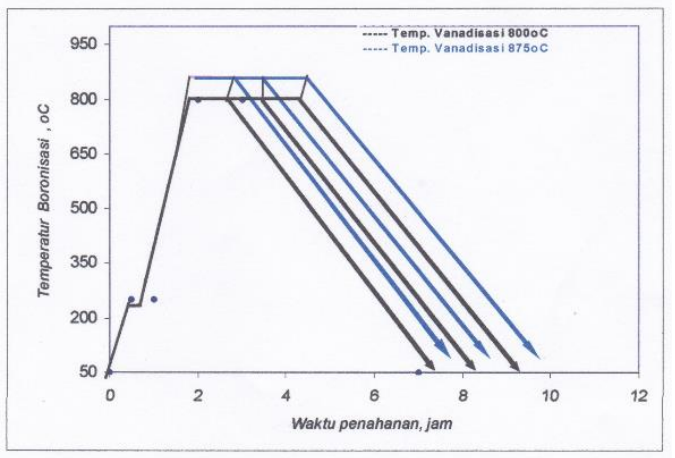

Gambar 3. Kurva pemanasan dan pendinginan pada proses laku panas.

Reaksi yang berlangsungan di dalam tabung pada saat proses vanadisasi adalah, sebagai berikut

Reaksi pertama ; NH4CI $\leftrightarrow \mathrm{NH}_{3(\mathrm{~g})}+\mathrm{HCI}_{(\mathrm{g})}$ Reaksi ke dua ; $2 \mathrm{HCI}+\mathrm{V} \leftrightarrow \mathrm{H}_{2(\mathrm{~g})}+\mathrm{VCI}_{2(\mathrm{~g})}$ Reaksi ke tiga : $\mathrm{V} \cdot \mathrm{CI}_{2(\mathrm{~g})}+\mathrm{Fe} \mathrm{CI}_{2(\mathrm{G})}+\mathrm{V}$ (at) Dimana :

$\mathrm{NH}_{3}$; ammoniak dalam bentuk gas

$\mathrm{H}_{2} \mathrm{O}$; air dalam bentuk gas

$\mathrm{Fe} \mathrm{CI}_{2}$; larutan ferri clorida dalam bentuk cair

\section{Pembahasan \\ Struktur Mikro}

Berdasarkan data hasil pengujian yang telah dilakukan, maka dapat dibahas beberapa hal yang meliputi: Struktur mikro sampel bahan awal (besi cor kelabu dan baja karbon), Diperoleh bahwa struktur mikro besi cor (BCK) memiliki fasa dengan matriks perlit sedikit ferit dan grafit lamelar dengan komposisi kimia (Tabel 4-1) terdiri atas: $4,16 \% \mathrm{C} ; 2,29 \% \mathrm{Si} ; 0,05 \%$ 5; $0,01 \% \mathrm{P}$;
0,056 \% Mn; 0,0 $19 \% \mathrm{Ni} ; 0,03 \% \mathrm{Cr} ; 0,02 \% \mathrm{Cu}$ dan $92,82 \% \mathrm{Fe}$, sedangkan struktur mikro baja karbon (BKR) memiliki fasa dengan matriks ferit dan perlit dengan komposisi kimia (Tabel 4-1) terdiri atas: $0,21 \% \mathrm{C} ; 0,27 \% \mathrm{Si} ; 0,02 \% \mathrm{P} ; 1,14 \%$ $\mathrm{Mn} ; 0,01 \% \mathrm{Ni} ; 0,03 \% \mathrm{Cr} ; 0,03 \% \mathrm{Al}$ dan $98,26 \%$ Fe.

Dari hasil pengamatan struktur mikro sampel bahan awal, besi cor kelabu adalah termasuk ke dalam jenis besi cor kelabu perlitik, sedangkan sampel bahan baja karbon yang dipakai dalam penelitian ini tergolong ke dalam jenis baja karbon rendah.

Setelah dilakukan proses vanadisasi pada temperatur $800^{\circ} \mathrm{C}$ dan $875^{\circ} \mathrm{C}$ dengan waktu penahan 1 jam, 3 jam dan 5 jam di dalam komposisi campuran bahan vanadisasi yang terdiri atas: Fe-V, $\mathrm{A}_{2} \mathrm{O}_{3}$, dan $\mathrm{NH}_{4} \mathrm{CI}$ pada perbandingan komposisi 60: $36,5: 3,5$.

Pada penelitian yang telah dilakukan dengan temperatur pemanasan $800^{\circ} \mathrm{C}$, terlihat adanya kedalaman difusi vanadium yang terbentuk dan kedalaman difusi ini terjadi pada sampel BCK dan BKR dengan lama penahanan I jam. Tebal masingmasing kedalaman difusi mencapai 0,64 jim untuk BCK dan 2,84 pm untuk BKR, sehingga dapat disimpulkan bahwa proses difusi pada temperatur pemanasan $800^{\circ} \mathrm{C}$ dapat benlangsung.

Untuk meningkatkan kedalaman difusi dapat dilakukan dengan menahan waktu pemanasan lebih lama lagi (3 - 5 jam) atau dengan menaikan energi aktivasinya dengan cara menaikan temperatur pemanasan $\left(875^{\circ} \mathrm{C}\right)$. Hal ini dibuktikan pada sampel dengan temperatur pemanasan $875^{\circ} \mathrm{C}$ dan waktu penahanan yang sama (1 jam), dimana proses difusi jauh Iebih cepat dan spesimen yang dipanaskan pada temperatur $800^{\circ} \mathrm{C}$. Difusi yang terbentuk menjadi lebih tebal masing-masing mencapai $0,94 \mu \mathrm{m}$ untuk BCK dan 7,66 $\mu \mathrm{m}$ untuk BKR. Hal ini terjadi karena energi yang diperlukan untuk menggetarkan atom-atom besi pada jarak yang Iebih besar tetap tercapai, sehingga memungkinkan atom-atom vanadium (V) berdifusi ke dalam atom besi lebih leluasa lagi. Sedangkan waktu penahanan berfungsi sebagai waktu berlangsungnya proses difusi. mi sesuai dengan hukum difusi sederhana, dimana semakin lama waktu penahanan. kedalaman difusi semakin tebal. Adapun difusi yang terbentuk dipermukan sampel adalah senyawa ferro vanadium (Fe2V). Senyawa ini terjadi berbentuk difusi putih (white layer). 
Difusi $\mathrm{Fe}_{2} \mathrm{~V}$ yang terbentuk akan semakin dalam dengan semakin tingginya temperatur atau semakin lamanya waktu penahanan, seperti ditunjukkan pada Gambar 4-6 sampel BCK-800 dengan waktu penahanan 3 jam dan Gainbar 4-16 sampel BKR800 dengan waktu penahanan 1 jam Dimana semakin lama waktu penahanan, difusi Fe2V yang terbentuk akan semakintebal.

Fenomena lain dan proses perlakuan panas, disamping untuk meningkatkan energi aktivasi dan vanadium (V) agar dapat berlangsung proses difusi ke dalam besi, juga dapat menguraikan karbidakarbida lain atau menguraikan ferit. Fasa perlit dapat terurai menjadi ferit atau mengubah struktur matriks dasar menjadi matriks ferit seperti terlihat pada Gambar 4-3. Hal ini terjadi karena pengaruh temperatur pemanasan. Dimana pada temperatur $800^{\circ} \mathrm{C}$ dan $875^{\circ} \mathrm{C}$, struktur mikro pada permukaan spesimen menunjukkan matriks ferit + perlit (ferit lebih dominan). Ini disebabkan karena semakin tinggi temperatur pemanasan, energi bebas karbon akan menuju ke arah negatif sehingga reaksi yang terjadi spontan.

Koefisien pendinginan pada temperatur pemanasan $875^{\circ} \mathrm{C}$ lebih cepat dari pada koefisien pendinginan pada temperatur pemanasan $800^{\circ} \mathrm{C}$. hal ini mengakibatkan grafit akan semakin kecil karena karbon akan lebih banyak yang berdifusi membentuk perlit, (Gambar 4-11). Sedangkan pada temeratur pemanasan $800^{\circ} \mathrm{C}$, karbon yang ada pada material besi cor akan dibentuk oleh $\mathrm{Si}$ menjadi grafit dan yang berdifusi dengan Fe akan semakin kecil sehingga membentuk fasa ferit.

Grafit pada proses difusi vanadium (V) secara interstisi tidak berlangsung atau atom $\mathrm{V}$ tidak dapat melewatinya, hal ini terjadi karena diameter atom $\mathrm{V}$ dan atom $\mathrm{C}$ mempunyai ukuran yang hampir sama (jari-jari atom $\mathrm{V}: 0,046 \mathrm{~nm}$ dan jarijari atom $\quad C: 0,077 \mathrm{~nm}$ ), sehingga proses difusi yang mungkin terjadi adalah subsitusi (menggantikan atom yang hilang). Karena proses difusi interstisi lebih mudah terjdi, maka atomatom vanadium (V) lebih reaktif berinterstisi dengan Fe dari pada bersubstitusi dengan $\mathrm{C}$.

\section{Kesimpulan}

Dari hasil pembahasan dapat di tarik kesimppulan sebagai berikut :

a. Uji Metallografi

Dari uji metallografi memperhatikan adanya kedalaman difusi pada permukaan sempel BCK dan BKR. b. Perhitungan kedalaman difusi

Dari perhitungan kedalaman difusi BCK memperhatikan bahwa kedalaman difusi terendah terdapat terhadap kode sample BCD$1 / 800$ sebesar0,00064 $\mathrm{mm}$. dan tertinggi pada BCK $-5 / 875$ sebesar $0,0029 \mathrm{~mm}$. Untuk BKR kedalaman difusi terendah terdapat pada kode sampel BKR -5/875 sebesar 0,00766 mm. Dengan demikian kenaikan kedalamandifusi pada sampe41 BCK dan BKR dipengaruhi oleh panambahan temperature dan waktu penahanan.

c. Pengujian kekerasan

Dari pengujian kekerasan sampel BCK memperhatikan nilai kekerasan permukaan terendah pada kode sampel BCK-1/800 sebesar $570 \mathrm{HV}$ dan tertinggi pada kode sampel CK5/875 sebesar 742 HV. Untuk BKR nilai Kekerasan terendah terdapat pada kode sampel BKR -1/875 sebesar $332 \mathrm{HV}$ dan tertinggi pada kode sampel BKR-5/876 sebesar $464 \mathrm{HV}$.

Dengan demiklian penigkatan kekerasan permukaan pada sampel BCK

Dipengaruhi oleh penambahan temperatur dan waktu penambahan.

Jika dilihat dari penambahan waktu penambahan waktu BKR untuk temperatur $800^{\circ} \mathrm{C}$, tidak terhubungan dengan penigkatan kekerasan. Tetapi penambahan waktu penambahan untuk temperatur $875{ }^{\circ} \mathrm{C}$ akan menigkatkan Kekerasan sampel. Dan jika dilihat dari penambahan temperatur sampel BKR ( $800{ }^{\circ} \mathrm{C}$ ke $875{ }^{\circ} \mathrm{C}$ ) dengan waktu penambahan waktu yang sama akan menigkatkan kekerasan sampel.

d. Pengujian ketahanan aus

Dari pengujian ketahanan aus sampel BCK memperlihatkan kehilangan berat tinggi pada kode sampel BCK-1/800 sebesar 0,0039 gr dan terendah pada kode sampel BCK-5/875 sebesar 0,0031 gr. Untuk BKR memperlihatkan kehilangan berat tinggi pada kode sampel BKR1/875sebesar 0,006 gr dan terendah pada kode sampel BKR 5/875 sebesar 0,0018 gr. Dengan demikian penigkatan ketahanan aus pad sampel BCK dan BKR dipengaruhi oleh penambahan temperatur dan waktu penahanan.

e. Penghitungan koiefisien difusi

Dari penghitungan koiefisen difusi sampel BCK memperlihatkan koiefisien difusi terendah pada sampel BCK $-1 / 800$ sebesar 
$5,760 \times 10^{-11} \mathrm{~cm}^{2} / \mathrm{sec}$ dan tertinggi pada kode sampel BCK $-5 / 875$ sebesar 2,33 $\mathrm{x} 10^{-11} \mathrm{~cm}^{2} / \mathrm{sec}$.Untuk BKR memperlihatkan koiefisien difusin terendah pada kode sampel BKR-5/800 sebesar $1,998 \times 10^{-11} \mathrm{~cm}^{2} / \mathrm{sec}$ dan tertinggi pada kode sampel BKR -5/875 2,719 $\mathrm{x} 10^{-11} \mathrm{~cm}^{2} / \mathrm{sec}$.

Dengan demikian penigkatan koiefiseien difusi pada BCK tidak dipengaruhi oleh

penambahan waktu penahanan untuk temperature yang sama. Tetapi penigkatan kofisien difusi pada sampel BCK dipengaruhi oleh penambahan temperatur $\left(800{ }^{\circ} \mathrm{C}\right.$ ke $875{ }^{\circ} \mathrm{C}$ ) untuk waktu penambahan yang sama.

Beberapa dengan samel BCK untuk semua sampel BKR penigkatan.

koeifisien difusi dipengaruhi oleh penambahan temperature dan waktu penahanan.

\section{DAFTAR PUSTAKA}

1. Adjiantoro B, "Peningkatan Kekerasan dan Ketahanan Aus Besi Cor Kelabu Melalui Proses Perlakuan Panas Kromisasi Padat", Tesis Pascasarjana ISTN,Jakarta, 2004.

2. Bela V. Kovacs, "Ductile Iron Heat Treatment", AFC Technical Center Livonia,, Michigan, 1962.

3. Boftrs, Thelnings K.E., "Steel and its Heat Treatment". Vol. III. Engineering and Special Steels.5thed.Wiley,NewYork, 1975.

4. Djaprie S., "Ilmu dan Teknologi Bahan", Erlangga, Jakarta, 1983.

5. Gray J.M., "Processing and Properties of Low Carbon Sleet'. The Metallurgical Society, New York, 1973.

6. Kraus G., "Principles of 1-feat Treatment of Steel", America Society for Metal, Metal Park Ohio, 1980.

7. Praktikum Metalografi, Pendidikan dan Latihan Metalografi Pusat Penelitian dan Pengembangan Metalurgi-LIPI dan P.T. Garuda Indonesia, Jakarta, 1986.

8. Pratowo B., "Peningkaian Kekerasan dan Kerahanan Aus Permukaan Baja Karbon Rendah dan Besi Cor Kelabu melalul Proses Boronisasi”, Tesis Pascasarjana ISTN, Jakarta, 2005.

9. Suhadi A. Dr. Jr. M.Eng., "Rekayasa
Permukaan Logam”, Seminar Sehari Teknologi dan Industri Program Pascasaijana Magister Teknik Mesin ISTN, Jakarta, 2004.

10. Surdia T. Ir. Prof. M.S.Met.E., "Pengetahuan Bahan Teknik”, Pradnya Paramita, Jakarta, 1995.

11. Surdia T. Jr. Prof. M.S.Met.E., "Teknik Pengecoran Logam ", Pradnya Paramita, Jakarta, 1991.

12. Zakharof B., "Heat Treatment of Metals", Foreign Languages Publishing House Moscow, Soviet Socialist Republics, 1962. 